\title{
Dandy Walker Variant and Bipolar I Disorder with Graphomania
}

\author{
Serdar Suleyman Can ${ }^{凶}$, Görkem Karakaş Uğurlu, and Selcen Çakmak \\ Ankara Atatürk Research and Training Hospital, Bilkent, Ankara, Turkey
}

Cerebellum is known to play an important role in coordination and motor functions. In some resent studies it is also considered to be involved in modulation of mood, cognition and psychiatric disorders. Dandy Walker Malformation is a congenital malformation that is characterized by hypoplasia or aplasia of the cerebellar vermis, cystic dilatation of the fourth ventricle and enlargement of the posterior fossa. When the volume of posterior fossa is normal, the malformation is called Dandy Walker Variant. Case is a 32 year old male with a 12 year history of Bipolar I Disorder presented with manic and depresive symptoms, including dysphoric and depressive affect, anhedonia, suicidal thoughts and behaviours, thoughts of fear about future, overtalkativeness and graphomania, increased energy, irregular sleep, loss of appetite, increased immersion in projects, irritability, agressive behavior, impulsivity. Cranial Magnetic Resonance Imaging was compatible to the morphological features of Dandy Walker Variant.

Psychiatry Investig 2014;11(3):336-339

Key Words Dandy walker, Bipolar disorder, Cerebellum.

\section{INTRODUCTION}

Cerebellum is known to play an important role in coordination and motor functions. ${ }^{1}$ In some resent studies it is also considered to be involved in modulation of mood, ${ }^{2}$ cognition and psychiatric disorders. ${ }^{3}$ From this aspect it is clear to understand that the cerebellum has a regulatory function on enhancing and suplementing other brain functions throughout direct and indirect circuits. ${ }^{4-6}$ According to different sources of evidence, the cerebellum may be altered in many psychiatric disorders including schizophrenia, bipolar disorder, unipolar depression, anxiety and attention deficit hyperactivity disorder. ${ }^{5,7}$

Dandy Walker Malformation is a congenital malformation that is characterized by hypoplasia or aplasia of the cerebellar vermis, cystic dilatation of the fourth ventricle and enlargement of the posterior fossa. When the volume of posterior fossa is normal, the malformation is called Dandy Walker Variant (DWV). ${ }^{8}$

Bipolar Disorder is a chronic and a life-long condition

\footnotetext{
Received: May 20, 2013 Revised: August 3, 2013

Accepted: August 29, 2013 Available online: July 21, 2014

$\triangle$ Correspondence: Serdar Suleyman Can, MD

Ankara Atatürk Research and Training Hospital, Bilkent street 3, Ankara 06800, Turkey

Tel: +05324091262, Fax: +90 31229127 26, E-mail: serdarsccan@yahoo.com

(a) This is an Open Access article distributed under the terms of the Creative Commons Attribution Non-Commercial License (http://creativecommons.org/licenses/by$\mathrm{nc} / 3.0$ ) which permits unrestricted non-commercial use, distribution, and reproduction in any medium, provided the original work is properly cited.
}

which is characterized by unusual shifts in mood state, energy level and behavior ${ }^{9}$ and psychotic symptoms such as hallucinations and delusions. ${ }^{10}$ Cerebellum is suggested to interfere in the pathophysiology of bipolar disorder. ${ }^{11}$ Cerebellum has connections via thalamus to the dorsolateral prefrontal cortex, medial prefrontal cortex, parietal and superior areas, anterior cingulate and the posterior hypothalamus. These are the areas associated with cognition and behavior. ${ }^{12,13}$

Cerebellum also has connections to limbic system that can provide changes in emotion and affects. ${ }^{14} \mathrm{~A}$ clinical study, 'cerebellar cognitive affective syndrome', patients with posterior and vermal cerebellar lesions were described to have executive dysfunctions, behavioral disinhibition and emotional dysregulation. ${ }^{15}$ In the literature there is a case report including a manic episode associated mega cisterna magna, a posterior fossa malformation which affects cerebellum. ${ }^{16}$

We aimed to report a case of a 32 year-old-man who has Bipolar I Disorder with Dandy Walker Variant.

\section{CASE}

The patient A, a 32 year old male with a 12 years history of Bipolar I Disorder presented with manic and depressive symptoms, including dysphoric and depressive affect, anhedonia, suicidal thoughts and behaviours, thoughts of fear about future, overtalkativeness and graphomania, increased energy, irregular sleep, loss of appetite, increased immersion in projects, irritability, agressive behavior, impulsivity in May 2013. He 
was complaining about decreased functionality, distractibility, sadness, thoughts of suiside, aggresivity, loss of interest to his environment, forgetfulness.

He had a history of three manic and a depressive episodes which he was diagnosed as Bipolar I Disorder. No alcohol and subtance abuse was reported.

The first episode of the disorder had come into existence with the delusions of grandiosity and reference, increased self esteem, hyperactivity, flight of ideas, impulsivity, irritability, decreased need for sleep when he admitted to an outpatient psychiatry clinic 12 years ago. At that time, he was diagnosed as 'psychotic disorder' and given antipsychotics (risperidone) and anticholinergic durg (biperiden). He went on a remission period, but incompliance occured. He undergone two other manic episodes especially including impulsivity, agressive behaviors, graphomania, overtalkativeness, distractibility and irritability. He was diagnosed as 'Bipolar I Disorder' and given mood stabilizators (Lithium carbonate, sodium valproat), antipsychotics (olanzapine, risperidone), anticholinergic drug (biperiden) and he stayed in hospital three times during that manic period.

On follow up visits he showed depressive and cognitive symptoms like depressive affect, decreased energy levels, psychomotor retardation, hypersomnia, unwillingness, attention and working memory deficits, anhedonia, hopelessness, thoughts of guilt and fear about future life. And then olanzapine and biperiden were stopped. When using citalopram some hypomanic symptoms like excessive talking, decreased need for sleep, euphoric affect and sexual disfunction occured. Then aripiprazole $10 \mathrm{mg} /$ day, bupropione $150 \mathrm{mg}$ /day were added to the treatment and citalopram was stopped day by day. In the following days he was hospitalized, because his symptoms didn't show a decline. When he was discharged from hospital, his treatment was aripiprazole $5 \mathrm{mg} /$ day, duloxetine $60 \mathrm{mg} /$ day, sodium valproate $1250 \mathrm{mg} /$ day. Cognitive and depressive symptoms repeated 3 months after discharging from hospital. His treatment was changed to lithium $1200 \mathrm{mg} /$ day, venlafaxine $225 \mathrm{mg} /$ day, quetiapine $600 \mathrm{mg} /$ day at outpatient clinic. On follow up he expressed depressive and hypomanic symptoms including dysphoric and depressive affect, anhedonia, suicidal thoughts and behaviours, thoughts of fear about future, overtalkativeness and graphomania, increased energy, irregular sleep, decreased appetide, increased immersion in projects, irritability, agressive behavior, impulsivity. Venlafaxine treatment was stopped for the reason of manic symptoms. He didn't show response to lithium carbonate therapy. So lithium carbonate treatment changed with sodium valproate.

Finally, he had been followed-up the inpatient clinic for two months in 2013 May to June. After 5 weeks treatment of so-

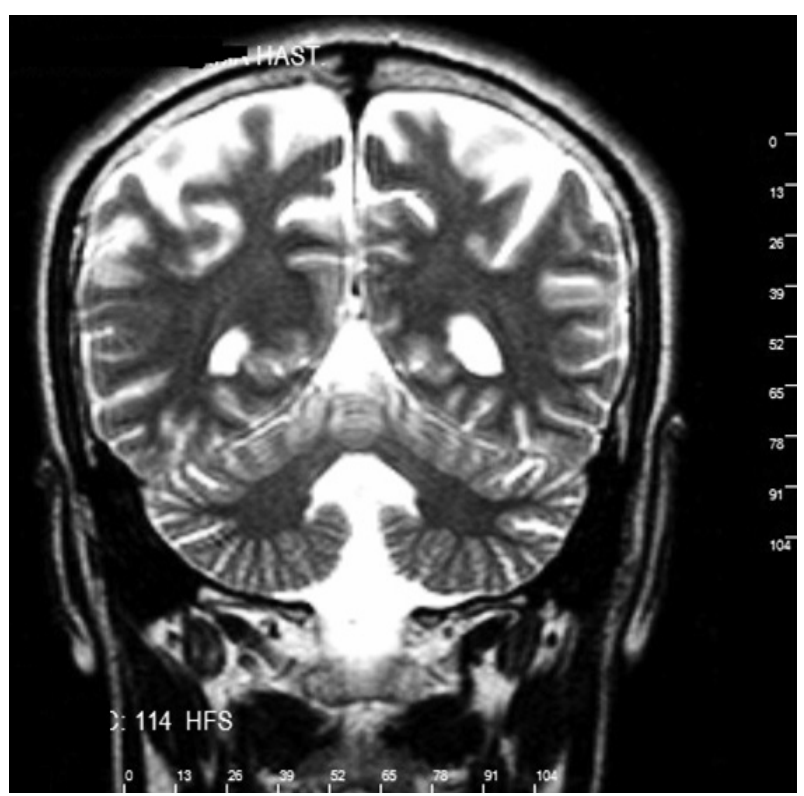

Figure 1. Enlargement of cisterna magna, 4th ventricle and vermian agenesia.

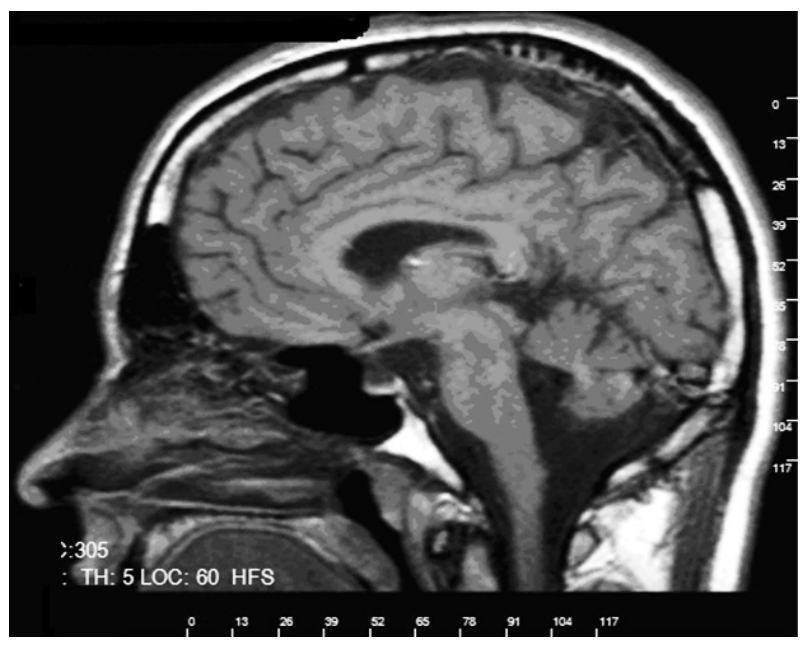

Figure 2. Enlargement of cisterna magna and other cisternal structures.

dium valproate $1250 \mathrm{mg} /$ day, quetiapine $500 \mathrm{mg} /$ day his depressive and manic symptoms improved well. On the other hand his cognitive symptoms like working memory, attention and learning deficit remained unchanged.

Neurological examination and electroensephalography were normal. Cranial Magnetic Resonance Imaging was compatible to the morphological features of Dandy Walker Variant. Bender Gestalt Visual Motor Sensation Scale (BGVMSS), Benton Visual Motor Memory Scale (BVMMS), Weschler Memory Scale (WMS) were applied to examine the organisity. Attention, working memory deficit and difficulty in learning were observed in WMS. BVMMS showed signs of cerebral organic pathology like significant turning mistakes and persevera- 


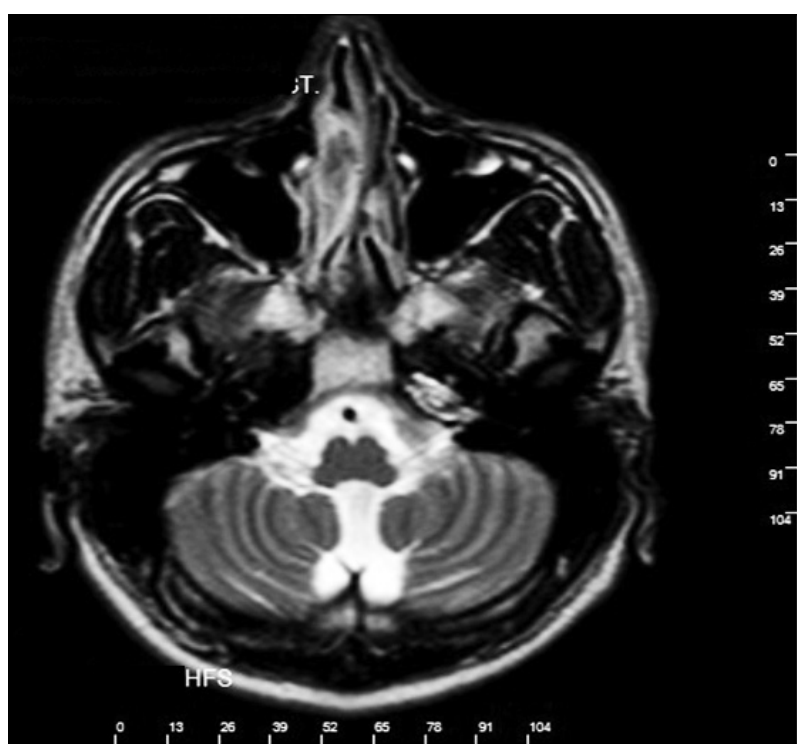

Figure 3. Cerebellar hemispheral hipoplasia and enlargement of foliums.

tions. All of them were compatible with a cerebral organic pathology. Young Mania Rating Scale (YMRS) performed before and after the treatment. During the treatment YMRS scores showed decrease from 26 to 13. Minnesota Multiphasic Personality Inventory (MMPI) was also administered to the patient. MMPI results were valid and showed an increase in hypocondriac and histrionic scales (Figures 1-3).

\section{DISCUSSION}

Mental symptoms have been associated with Dandy Walker Variant in recent studies. A large variety of mental symptoms ranging from psychotic to cognitive and emotional were defined earlier. ${ }^{17,18}$ Although Dandy Walker Syndrome is usually detected in the early childhood, the patient did not state any neurologic symptom till 20 years.

Cerebellar vermis neurons plays a role in mood modulation..$^{19}$ Cerebellar vermis pathologies may be associated with changes of mood and behaviors. ${ }^{20}$ In this case we diagnose Bipolar I Disorder presented with emotional, behavioral and cognitive changes with a cerebellar vermian and hemispheral atrophy and mega cysterna magna. This case may contibute to the association between cerebellar vermian pathology and behavioral, mood and cognitive changes.

Hypergraphy is an inappropriate and a permenant writing behavior. It is considered to be a compulsive activity that results from the lesions of globus pallidus and bilateral frontal lobes. ${ }^{21}$ Hypergraphy have been reported about $8 \%$ of patients who had temporal lobe epilepsy. It is also a symptom of manic and hypomanic episodes of Bipolar Disorder. ${ }^{22}$ In addition to these knowledges compulsive writing behavior can be ob- served in schizophrenia and frontotemporal dementia. ${ }^{10}$ In light of the review of the literature, any studies couldn't be found about the association between dandy walker variant or other cerebellar malformations and hypergraphy.

Neuropsychiatric studies supports that the cognitive symptoms like language (including speech perception, lexical retrieval and working memory), temporal processing, implicit learning and memory and visual spatial attention defficits may be a result of cerebellar lesions, ${ }^{23}$ but the role of cerebellum in the cognitive process have not been clearly known. ${ }^{9}$ In the present case Weschler Memory Scale was applied to the patient and as a result; attention, working memory and learning deficits were observed. These findings compatible with the idea of association between cerebellar pathology and attention, learning and memory deficits.

\section{REFERENCES}

1. Schmahmann JD. An emerging concept. The cerebellar contribution to higher function. Arch Neurol 1991;48:1178-1187.

2. Brambilla P, Harenski K, Nicoletti M, Mallinger AG, Frank E, Kupfer DJ, et al. MRI study of posterior fossa structures and brain ventricles in bipolar patients. J Psychiatry Res 2001;35:313-322.

3. Schmahman JD. Disorders of the cerebellum: ataxia, dysmetria of thought, and the cerebellar cognitive affective, syndrome. J Neuropsychiatry Clin Neurosci 2004;16:367-378.

4. Andreasen NC, Pierson R. The Role of the cerebellum in schizophrenia. Biol Psychiatry 2008;64:81-88.

5. Schmahmann JD, Weilburg JB, Sherman JC. The neuropsychiatry of the cerebellum-insights from the clinic. Cerebellum 2007;6:254-267.

6. Ribas GC. Neuroanatomic basis of behavior: history and recent contributions. Rev Bras Psiquiatr 2007;29:63-71.

7. Bugalho P, Correa B, Viana-Baptista M. Role of the cerebellum in cognitive and behavioural control: scientific basis and investigation models. Acta Med Port 2006;19:257-267.

8. Mytilinaios DG, Tsamis KI, Njau SN, Polyzoides K, Baloyannis SJ. Neuropathological findings in Dandy Walker variant. Dev Neurorehabil 2010;13:64-67.

9. Baldaçara L, Borgio JGF, Lacerda ALT, Jackowski AP. Cerebellum and psychiatric disorders. Rev Bras Psiquiatr 2008;30:281-289.

10. Goes FS, Sadler B, Toolan J, Zamoizki RD, Modimore FM, Mackinron DF, et al. Psychotic features in bipolar and unipolar depression. Bipolar Disord 2007;9:901-906.

11. Strakowski SM, Adler CM, DelBello MP. Volumetric MRI studies of mood disorders: do they distinguish unipolar and bipolar disorder? Bipolar Disord 2002;4:80-88.

12. Dolan RJ. A cognitive affective role for the cerebellum. Brain 1998;121: 545-546.

13. Middleton FA, Strick PL. Cerebellar output channels. Int Rev Neurobiol 1997;41:61-82.

14. Schutter DJ, van Honk J. The cerebellum on the rise in human emotion. Cerebellum 2005;4:290-294.

15. Schmahmann ID, Sherman JC. The cerebellar cognitive affective syndrome. Brain 1998;121:561-579.

16. Turan T, Beşirli A, Asdemir A, Özsoy S, Eşel E. Manic episode associated with mega cisterna magna. Psychiatry Investig 2010;7:305-307.

17. Turner SJ, Poole R, Nicholson MR, Ghadiali EJ. Schizophrenia like psychosis and Dandy-Walker variant. Schizophr Res 2001;48:365-367.

18. Ferentinos PP, Kontaxakis VP, Havaki-Kontaxaki BJ, Paplos KG, Papa DA, Soldatos CR. Refractoriness to psychosis andprominent cognitive- 
deficits in a patient with mega-cisterna magna. Prog Neuropsychopharmacol Biol Psychiatry 2007;31:561-563.

19. Mills NP, Delbello MP, Adler CM, Stracowski SM. MRI analysis of cerebellar vermal abnormalities in bipolar disorder. Am J Psychiatry 2005; 162:1530-1532.

20. Richter S, Schoch B, Kaiser O, Groetschel H, Dimitrova A, Hein-Kropp C, et al. Behavioral and affectve changes in children and adolescents with chronic cerebellar lesions. Neurosci Lett 2005;381:102-107.
21. Cambier J, Masson C, Benammou S, Robine B. Graphomania. Compulsive graphic activity as a manifestation of fronto-callosal glioma. Rev Neurol (Paris) 1988;144:158-164.

22. Schachter SC, Holmes GL, Kasteleijn-Nolst Trenite DGA. Behavioral Aspects of Epilepsy: Principles. NewYork: Demos Medical Publishing; 2008.

23. Justus TC, Ivry RB. The cognitive neuropsychology of the cerebellum. Int Rev Psychiatry 2001;13:276-282. 